\title{
The Effect of Synthesis Temperature on Carbon Nanospheres from Palm Kernel Fiber
}

\author{
Oluwafemi E. Ige*, Freddie L. Inambao', Gloria A. Adewumi \\ Department of Mechanical Engineering, University of Kwazulu-Natal, Durban, South Africa.
}

${ }^{1}$ 0000-0001-9922-5434 (Freddie Inambao)

\begin{abstract}
Carbon nanospheres (CNS) were synthesized successfully from palm kernel fiber activated carbon. Palm kernel fiber (PKF) which is an agro-waste was carbonized followed by physical activation with $\mathrm{CO}_{2}$, then go along with treated utilizing ethanol vapor at temperature of $700{ }^{\circ} \mathrm{C}, 850{ }^{\circ} \mathrm{C}$ and $1000{ }^{\circ} \mathrm{C}$. The temperature effect on developed synthesized nanomaterials was investigated using scanning Fourier transform infrared microscopy (FTIR), electron microscopy (SEM), energy dispersive x-ray spectroscopy (EDX), transmission electron microscopy (TEM), x-ray diffraction (XRD), and thermo-gravimetric analysis (TGA). The temperatures were varied from $700{ }^{\circ} \mathrm{C}$ to $1000{ }^{\circ} \mathrm{C}$ with intervals of $150{ }^{\circ} \mathrm{C}$. The SEM results showed highest purity and the largest number of carbon-nanospheres being formed at a synthesis temperature of $1000{ }^{\circ} \mathrm{C}$. The results indicate that CNS diameter, growth rate, crystallinity and density can be affected by increase in temperature. The CNS diameters were found to increase when the synthesis temperature increased. The results of the TEM showed that, within the temperature range of $700{ }^{\circ} \mathrm{C}$ to $1000{ }^{\circ} \mathrm{C}$, the $\mathrm{CNSs}$ diameter increased continuously from $3 \mathrm{~nm}$ to $65 \mathrm{~nm}$. XRD analysis showed that the synthesized carbon nanomaterials were amorphous. In general, the results showed that the synthesis temperature affects the diameter, density and crystallinity of carbon nanomaterials. The synthesis temperature of $1000{ }^{\circ} \mathrm{C}$ appears to be the ideal temperature for high quality and high yield CNSs production. The presence of iron $(\mathrm{Fe})$ in the EDX results showed that such synthesized CNSs can be used as reinforcement materials in the manufacture of automobile brake pads.
\end{abstract}

Keywords: Carbon nanosphere, characterization, bio-based precursors, temperature

\section{INTRODUCTION}

The increasing need for more environmentally friendly and biodegradable material requires the development of nanomaterials.

Since Iijima's innovation of multi-walled carbon nanotubes in 1991, global enthusiasm in academic and industrial circles for carbon nanotubes (CNTs) and their distinctive characteristics has been high because of their nanoscale structures [1] Carbonbased nanostructures with various morphologies have created great interest in scientific research due to their outstanding and distinctive characteristics. The attention of scientists around the world has been drawn to research on new material technology, development and improvement of materials properties and the discovery of alternative precursors that impart the desired properties to the materials.

Chemical vapor deposition (CVD) [2, 3], laser ablation [4], and arc discharge [5] are the commonly used synthesis methods to produce CNTs. Among the variety of synthetic methods, CVD is the most effective technique for large-scale CNTs $[6,7]$. The capability to grow nanotubes exactly on the nanomaterials by using the CVD method allows sufficient control for production of high purity nanotubes. The quantity of carbon that enables better CNT nucleation is reduced as particle size decreases [8$10]$.

Since the innovation of carbon nanotubes, carbon nanoparticles carbon nanofibers, and carbon nanostructures are becoming commercially significant and their importance has grown rapidly over the past decade. CNTs have been widely examined due to their unique mechanical, magnetic and electronic properties [11-13]. The CNTs are regarded as possible filler materials to enhance the mechanical properties as well as physical properties of polymer composites [14]. CNT applications are eco-friendly and offer good opportunities as well as new technology for various sectors which include biotechnology, aerospace, automotive and electronics industries.

By using ethanol as the carbon resource in the CVD method has positive impacts for instance, low temperature reaction, high product purity and the potential for reduced cost for largescale production $[15,16]$. Generally, the temperature of synthesis is a factor affecting crystallinity [17], density [18], diameter, growth rate [17-20], yield, morphology [21, 22] and purity [23] of nanomaterials. Investigations of temperature effect on CNT growth parameters have shown that the temperature range from $800{ }^{\circ} \mathrm{C}$ to $1000{ }^{\circ} \mathrm{C}$ is the optimal temperature which results in the highest yield of CNTs [23, 24]. When the temperature increases from $750{ }^{\circ} \mathrm{C}$ to $950{ }^{\circ} \mathrm{C}$ the 
diameter, crystallinity, growth rate and density of CNTs can be measured and high levels of crystalline perfection can be achieved at temperature of $950{ }^{\circ} \mathrm{C}$ [18]. The interchange of temperature from $700{ }^{\circ} \mathrm{C}$ to $830^{\circ} \mathrm{C}$ has been shown to result in structural defects in CNTs and graphite sheets grown [25].

Muataz et al. [20] varied the temperatures reaction of CNT from $500{ }^{\circ} \mathrm{C}$ to $850{ }^{\circ} \mathrm{C}$ and the result indicated that $\mathrm{CNT}$ growth was seen from $600{ }^{\circ} \mathrm{C}$ and high purity was obtained at a temperature of $850{ }^{\circ} \mathrm{C}$. The study by Lee et al. [19] showed that the thicker layers of the compartment appear at $1100{ }^{\circ} \mathrm{C}$ more frequently. When the temperature gradually increased from $850^{\circ} \mathrm{C}$ to $1100^{\circ} \mathrm{C}$, the comparative amount of crystalline graphitic sheets also increased. Toussi et al. [26] showed that a small amount of CNTs were formed at temperatures below 700 ${ }^{\circ} \mathrm{C}$, while more shapeless carbons were formed in the CNTs at temperatures above $900{ }^{\circ} \mathrm{C}$. Their study found that the optimum temperature for CNT growth was between $800{ }^{\circ} \mathrm{C}$ and $900{ }^{\circ} \mathrm{C}$ and the ideal temperature growth was at $850{ }^{\circ} \mathrm{C}$. Pham et al. [27] reported that below the synthesis temperature of $800{ }^{\circ} \mathrm{C}$, tube length growth and diameter was minimal, while the highest tube crystallinity was achieved at a temperature range between $800{ }^{\circ} \mathrm{C}$ and $840{ }^{\circ} \mathrm{C}$. Madani et al. [17] presented the temperature effect variation on the growth of CNTs utilizing CVD and the results revealed that the CNTs diameters increased when the temperature of synthesis increased, but the CNTs growth crystallinity decreased.

Zhao et al. [28] revealed that the CNTs multiplied quicker as the temperature increased, while the catalyst showed a significant increase for a little while, followed by a decrease. As temperature increased from $805{ }^{\circ} \mathrm{C}$ to $830{ }^{\circ} \mathrm{C}$, the crystallinity improved a little while the height and the yield of CNT forests tripled in the course of increasing from $800{ }^{\circ} \mathrm{C}$ to $1100{ }^{\circ} \mathrm{C}$. Shamsudin et al. [24] achieved $99.99 \%$ optimum growth at a temperature of $900^{\circ} \mathrm{C}$. According to Jiang and Lan [29], at a low temperature of $450{ }^{\circ} \mathrm{C}, \mathrm{CNT}$ s can be synthesized from carbonaceous solids, as opposed to high temperature synthesis. This paper presents the result of the temperature effect on synthesis of carbon nanomaterials at $700{ }^{\circ} \mathrm{C}, 850{ }^{\circ} \mathrm{C}$ and $1000{ }^{\circ} \mathrm{C}$ for $30 \mathrm{~min}$ treated with ethanol vapor. In the manufacturing of CNTs, nanospheres and nanosheets, the synthesis temperature performs a significant role. Generally, the temperature of synthesis is a factor that affects the final purity, morphology and yield of a nanomaterial.

\section{EXPERIMENTAL PROCEDURE}

The material used in this study was palm kernel fiber (PKF) of the Elaeis guineensis species and was obtained from a local palm oil mill in Ado Ekiti, Nigeria, after extraction of the oil. PKF was washed with hot water to remove leftover red oil and sun dried for 60 days. The PKF were placed in a quartz tube (heat-resistant) in a horizontal (MTF 12/38/400: Model) tube furnace to produce carbon nanospheres (CNSs). PKF carbonization was done at $600{ }^{\circ} \mathrm{C}$ for $120 \mathrm{mins}$ in an inert atmosphere. In the experimental procedure $15 \mathrm{~g}$ of PKF was stored in a quartz tube and heated to the desired reaction temperature in a horizontal furnace at $5{ }^{\circ} \mathrm{C} \mathrm{min}{ }^{-1}$ heating rate until carbonized. This was followed by physical activation with $\mathrm{CO}_{2}$, for $60 \mathrm{~min}$, then treated at $700{ }^{\circ} \mathrm{C}, 850{ }^{\circ} \mathrm{C}$ and $1000{ }^{\circ} \mathrm{C}$ for $30 \mathrm{~min}$ using ethanol vapor. Ethanol was used to generate an aerosol using an ultrasonic (GMH-200: Type) air humidifier which operated at $50 \mathrm{~Hz}$. Nitrogen gas was gone through the aerosol in order to generate a inert air for reaction and deliver the of drops aerosol to the reactor space. At the desired temperature the aerosol line was shut, allowing the nitrogen gas to cool the system.

\section{MATERIAL CHARACTERIZATION}

The morphology of the synthesized CNS was investigated utilizing FEGSEM (Zeiss, Germany Model: Ultra Plus) with an EDX in-built which was used for elemental composition analysis. The sample phase identification and microstructure were examined using JEOL 1400 TEM and a JEOL HRTEM 2100 model at a speed voltage of $20 \mathrm{kV}$. The sample of CNS needed for HRTEM measurements was approximately 0.0002 $\mathrm{g}$ mixed with ethanol using an $80 \mathrm{~Hz}$ Watt transistorized sonic cleaner for $20 \mathrm{~min}$. The TEM preparation of the carbon nanosphere mixed with ethanol was achieved by putting a droplet of the solution on formvar with painted 150 meshes of copper grids. The TEM sample was dry at lower temperature and watched at $100 \mathrm{kV}$ speed voltage.

For TEM, the iTEM software and Gatan camera were used to store and process the images taken digitally from the camera (Megaview III). The backloading preparation method was used for the preparation of XRD samples of the PKF nanomaterial. The Netherlands made PANalytical Empyrean Diffractometer with a Co-K $\alpha$ radiation and $\mathrm{X}^{\prime}$ Celerator detector was used to analyze the sample. The generator configuration was $40 \mathrm{kV}$ and $40 \mathrm{~mA}$. A PerkinElmer Product was used to study the FTIR of the sample. A PerkinElmer synchronized thermal analyzer (STA) 6000 was used to establish the thermal stability of the synthesized nanosphere material.

\section{RESULTS AND DISCUSSION}

\section{A. SEM}

Increasing the temperature of the furnace can increase the frequency of impact of the elements found in carbon activated PKF resulting in various structures being formed as shown in Fig. 1. 

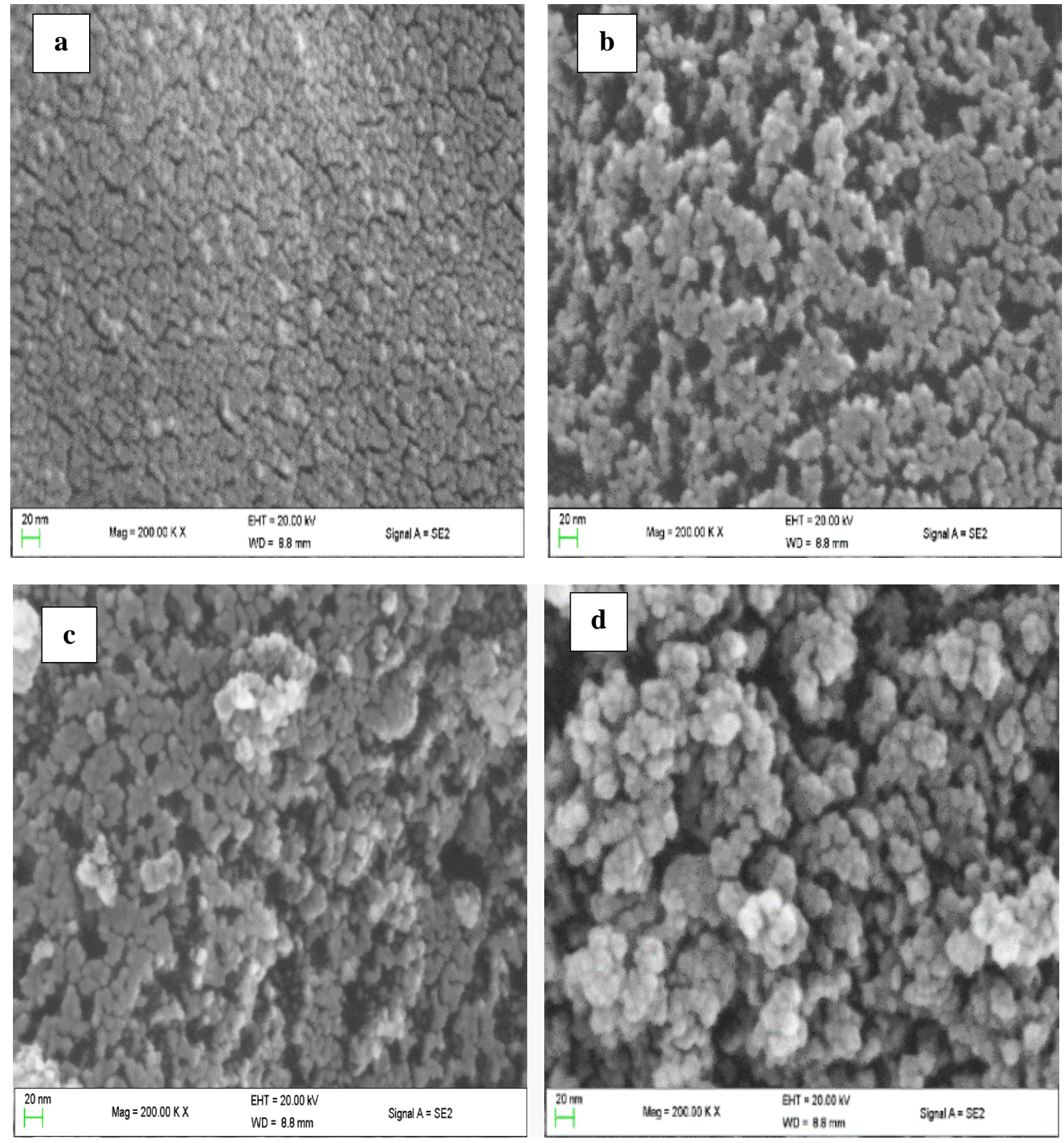

Fig. 1 SEM images of (a) PKF carbon activated, synthesized nanomaterials at (b) $700{ }^{\circ} \mathrm{C}$ (c) $850{ }^{\circ} \mathrm{C}$ and (d) $1000{ }^{\circ} \mathrm{C}$

Fig. 1 (b-d) shows the SEM images of CNS produced from PKF at different buildup temperatures $700{ }^{\circ} \mathrm{C}, 850{ }^{\circ} \mathrm{C}$ and $1000{ }^{\circ} \mathrm{C}$. FEGSEM and HRTEM were used to characterize the temperature effect on the synthesized nanomaterials developed. Fig. 1a shows the SEM image of physically activated PKF produced at $850^{\circ} \mathrm{C}$ for $60 \mathrm{~min}$ under $\mathrm{CO}_{2}$. The micrographs SEM image from Fig. $1 \mathrm{~b}$ to $\mathrm{d}$ present carbon sheets, carbonnanoparticles (CNPs) and carbon-nanospheres (CNSs). The SEM image at $700{ }^{\circ} \mathrm{C}$ from Fig. $1 \mathrm{~b}$ indicates the presence of tiny sphere particles or sheet-like structure grown with irregular morphology. Low density nanospheres with small diameter ranging from $3 \mathrm{~nm}$ to $20 \mathrm{~nm}$ were formed. This indicates that the synthesis temperature of $700{ }^{\circ} \mathrm{C}$ was not enough to produced carbon nanospheres/nanotubes. At the temperature of $850^{\circ} \mathrm{C}$, a small sphere-like morphology was noticed as shown in Fig. 1c. At this temperature several carbon nanospheres with small quantities of amorphous carbon were developed.

The results showed a huge increase in hydrocarbon pyrolysis with particle distribution size ranging $10 \mathrm{~nm}$ to $65 \mathrm{~nm}$ when the synthesis temperature increased from $850{ }^{\circ} \mathrm{C}$ to $1000{ }^{\circ} \mathrm{C}$, as shown in Figure 1d. Increasing the temperature to $1000{ }^{\circ} \mathrm{C}$ produced clean nanospheres with aligned and uniform diameter distribution size. The SEM micrographs of all developed 
samples display a strong difference in the structure of the synthesized materials at the different temperatures. Thus, the morphological analysis under atmospheric pressure showed that the temperature build-up played an important role in the synthesis of uniform CNSs.

\section{B. Elemental Composition Analysis}

A FEGSEM built-in with EDX was employed to analyze the activated carbon elemental composition and synthesized nanomaterials at different temperatures. Table I shows the PKF activated carbon EDX analysis and synthesized nanomaterials at temperatures of $700{ }^{\circ} \mathrm{C}, 850{ }^{\circ} \mathrm{C}$ and $1000{ }^{\circ} \mathrm{C}$. From the table there is a high carbon content in all samples with the highest yield for all synthesis temperatures from nanomaterials synthesized at $850{ }^{\circ} \mathrm{C}$. After the carbonized PKF was physically activated at $850{ }^{\circ} \mathrm{C}$ under $\mathrm{CO}_{2}$, it was followed by treatment for $30 \mathrm{~min}$ with ethanol vapor to produce carbon nanospheres. This temperature has the highest carbon nanomaterials yield because the synthesis temperature is high enough to produce carbon nanospheres while also decreasing amorphous carbon. In addition, EDX showed a high carbon content of $88.10 \%, 90.06 \%$ and $89.40 \%$ respectively in all synthesized carbon nanosphere samples; this confirmed the treatment of the nanomaterials with ethanol vapor. From Table I it is evident that as the synthesis temperature increased the oxygen content reduced which agrees with previous results obtained [30].

Table I. EDX analysis of PKF carbon activated, and nanomaterials at the different temperature

\begin{tabular}{|c|c|c|c|c|}
\hline Element & $\begin{array}{c}\text { Activated } \\
\text { Carbon } \\
\text { Wt.\% }\end{array}$ & $\begin{array}{c}\text { Nanomaterial } \\
\text { Synthesized at } \\
\mathbf{7 0 0}^{\circ} \mathrm{C} \\
\text { Wt. } \%\end{array}$ & $\begin{array}{c}\text { Nanomaterial } \\
\text { Synthesized at } \\
\mathbf{8 5 0}^{\circ} \mathrm{C} \\
\text { Wt. } \%\end{array}$ & $\begin{array}{c}\text { Nanomaterial } \\
\text { Synthesized at } \\
1000^{\circ} \mathrm{C} \\
\text { Wt. } \%\end{array}$ \\
\hline $\mathrm{C}$ & 87.59 & 88.10 & 90.06 & 89.40 \\
\hline $\mathrm{O}$ & 7.80 & 6.85 & 6.76 & 6.52 \\
\hline $\mathrm{Mg}$ & 0.79 & 0.76 & 0.54 & 1.27 \\
\hline $\mathrm{Al}$ & 0.32 & 0.97 & 0.52 & 1.17 \\
\hline $\mathrm{Si}$ & 0.97 & 1.29 & 0.57 & - \\
\hline K & 1.09 & 1.53 & 1.20 & 1.12 \\
\hline $\mathrm{Fe}$ & 0.23 & 0.50 & 0.34 & 0.52 \\
\hline $\mathrm{Cu}$ & 1.20 & - & - & - \\
\hline Total & 100.00 & 100.00 & 100.00 & 100.00 \\
\hline
\end{tabular}

The elemental composition in PKF carbon activated for $\mathrm{CF}$ included oxygen $(\mathrm{O})$, carbon $(\mathrm{C})$, and potassium $(\mathrm{K})$, which are normally originated from plants. The existence of oxygen in all samples developed can be credited to the carbonized PKF physically activated under $\mathrm{CO}_{2}$ and ethanol aerosol. The existence of silicon ( $\mathrm{Si}$ ) was noticed in the synthesized nanomaterials which can be attributed to the reaction of the material in the quartz tube. The results from both FESEM and EDX established that the samples produced form PKF activated carbon are carbon nanospheres. The presence of iron (Fe) in all the samples as seen in Table I showed that the nanomaterial can be used as additive materials in the production of brake pads.

\section{High-Resolution TEM (HRTEM)}

The TEM analysis was conducted using a JEOL HRTEM 2100 model to study the morphological changes and the material deflections and the actual transition that appears in the carbon nanomaterial structure. Fig. 2(c) shows small quantities of $\mathrm{CNSs}$ at $850{ }^{\circ} \mathrm{C}$ with particle size distribution as seen in the TEM image varying from $10 \mathrm{~nm}$ to $40 \mathrm{~nm}$ diameter; however, the sphere structure was not clearly identified. At this temperature, increased numbers of CNSs with a smaller amount of deformation and a higher CNS yield was observed with fewer impurities.

As seen in Fig. 2(c), the TEM images show uniform nanosphere sizes, while some nanospheres have some deformation and are very weak. The TEM at $1000{ }^{\circ} \mathrm{C}$ as seen in Figure 2 (d) shows that high purity and high yield CNSs were formed with high agglomeration. The distribution size diameter of nanospheres range from $10 \mathrm{~nm}$ to $65 \mathrm{~nm}$, while nanospheres with $25 \mathrm{~nm}$ to $35 \mathrm{~nm}$ diameter occur at a higher frequency than those of $40 \mathrm{~nm}$ to $65 \mathrm{~nm}$ diameter. 
International Journal of Engineering Research and Technology. ISSN 0974-3154, Volume 13, Number 11 (2020), pp. 3099-3108

(C) International Research Publication House. https://dx.doi.org/10.37624/IJERT/13.11.2020.3099-3108
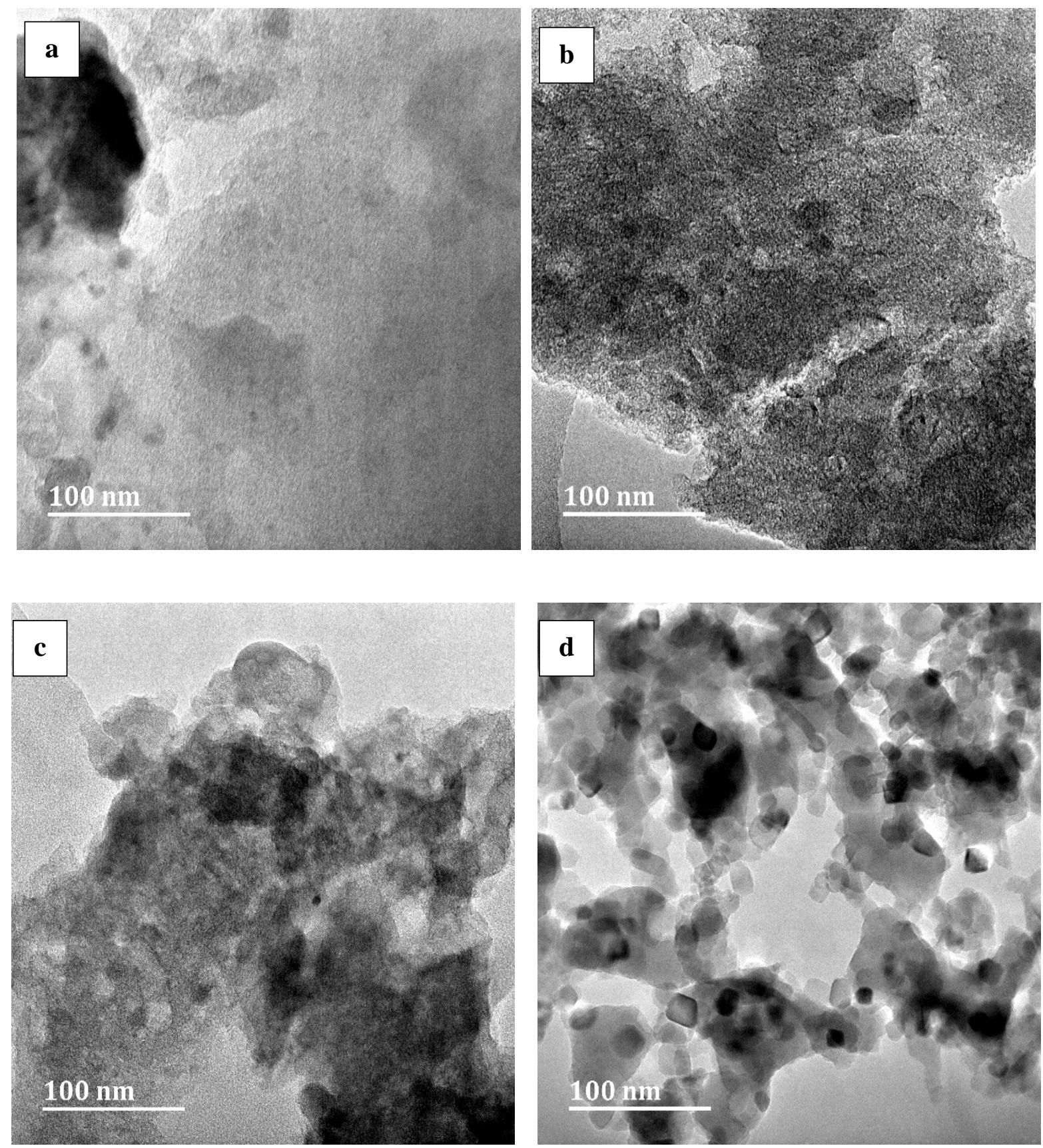

Fig. 2: TEM images of (a) PKF carbon activated, synthesized nano materials at (b) $700{ }^{\circ} \mathrm{C}$ (c) $850{ }^{\circ} \mathrm{C}$ and (d) $1000{ }^{\circ} \mathrm{C}$

At $700{ }^{\circ} \mathrm{C}$, the absence of carbon nanomaterial growth indicates that the temperature at that level was not adequate high to transform the PKF carbon activated into tubes or spheres. As ethanol vapor was added and the temperature increased, the state of PKF activated carbon content in the tube was modified, thereby activating the carbon nanospheres growth on carbon activated. It was noticed that temperature of $1000{ }^{\circ} \mathrm{C}$ is appropriate to develop nanospheres.

\section{XRD Analysis}

The structural characterization of carbon nanomaterial samples at different synthesis temperatures was achieved using XRD technique using the Netherlands made PANalytical Empyrean Diffractometer including $\mathrm{Co}-\mathrm{K} \alpha$ radiation and $\mathrm{X}^{\prime}$ Celerator detector. Fig. 3 is the XRD pattern obtained from activated carbon at $850{ }^{\circ} \mathrm{C}$ for $60 \mathrm{~min}$ and synthesized nanomaterials at temperature for $30 \mathrm{~min}$. All the synthesized nanomaterials result at $700{ }^{\circ} \mathrm{C}, 850{ }^{\circ} \mathrm{C}$ to $1000{ }^{\circ} \mathrm{C}$ displayed two major broad diffraction peaks in Fig. 3 (b-d). The $2 \Theta$ value $(002)$ diffraction peak was found at $22.11^{\circ}$, whereas the (101) diffraction peak was discovered at $42.96^{\circ}$, indicating hexagonal graphite structural planes. 
International Journal of Engineering Research and Technology. ISSN 0974-3154, Volume 13, Number 11 (2020), pp. 3099-3108

(C) International Research Publication House. https://dx.doi.org/10.37624/IJERT/13.11.2020.3099-3108

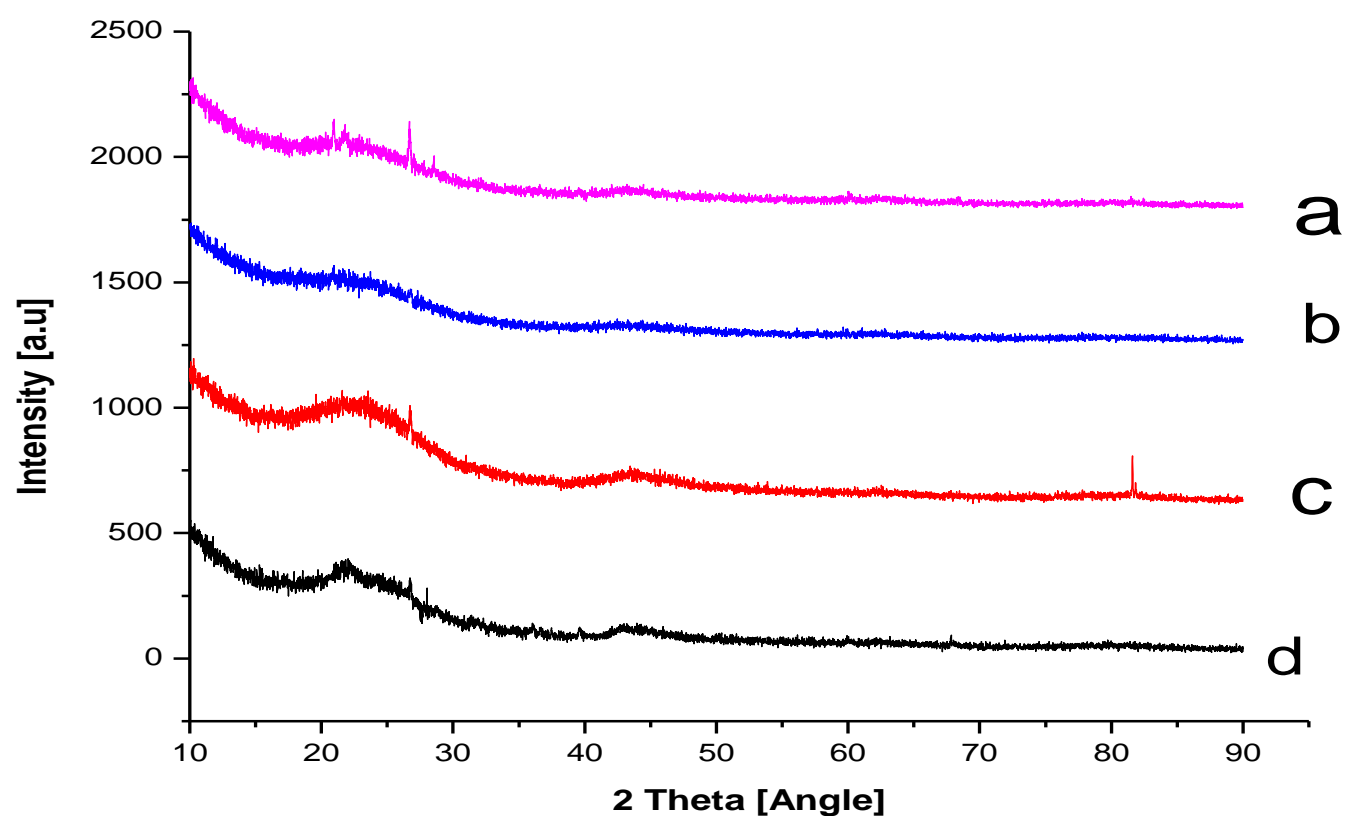

Fig. 3 XRD of (a) PKF carbon activated, synthesized nanomaterials at (b) $700{ }^{\circ} \mathrm{C}$ (c) $850{ }^{\circ} \mathrm{C}$ and (d) $1000{ }^{\circ} \mathrm{C}$

The peak located at (002) confirmed the presence of lignin and hemicellulose contents found in PKF and all the samples were amorphous in nature. These two peak values exhibit low crystallinity and high amorphous carbon structure of the nanomaterials sample and are in accordance with results from other studies [23, 29].

\section{E. SAED}

The HRTEM was utilized to establish the effect of temperature on crystallinity of nanomaterials. Fig. 4 shows the image of the SAED and HRTEM rings of the nanospheres produced in the research. From Fig. 4(a) and (c) it is evident that the CNSs have a strongly regular crystalline structure. The HRTEM reveals a small portion of nanosphere grown at temperature of $850{ }^{\circ} \mathrm{C}$ and a graphite structure near the edge of the sphere as shown in Fig. 4(a). Increasing in temperature from $850{ }^{\circ} \mathrm{C}$ to $1000{ }^{\circ} \mathrm{C}$, the HRTEM image of CNS showed that most CNSs were formed at unique depths with sphere curves as shown in Fig. 4(c). The SAED pattern has wide diffraction rings that show the presence of nanosphere crystallinity and graphitic nature which agrees with the planes (002) and (101) and displays agreement with the results from XRD.
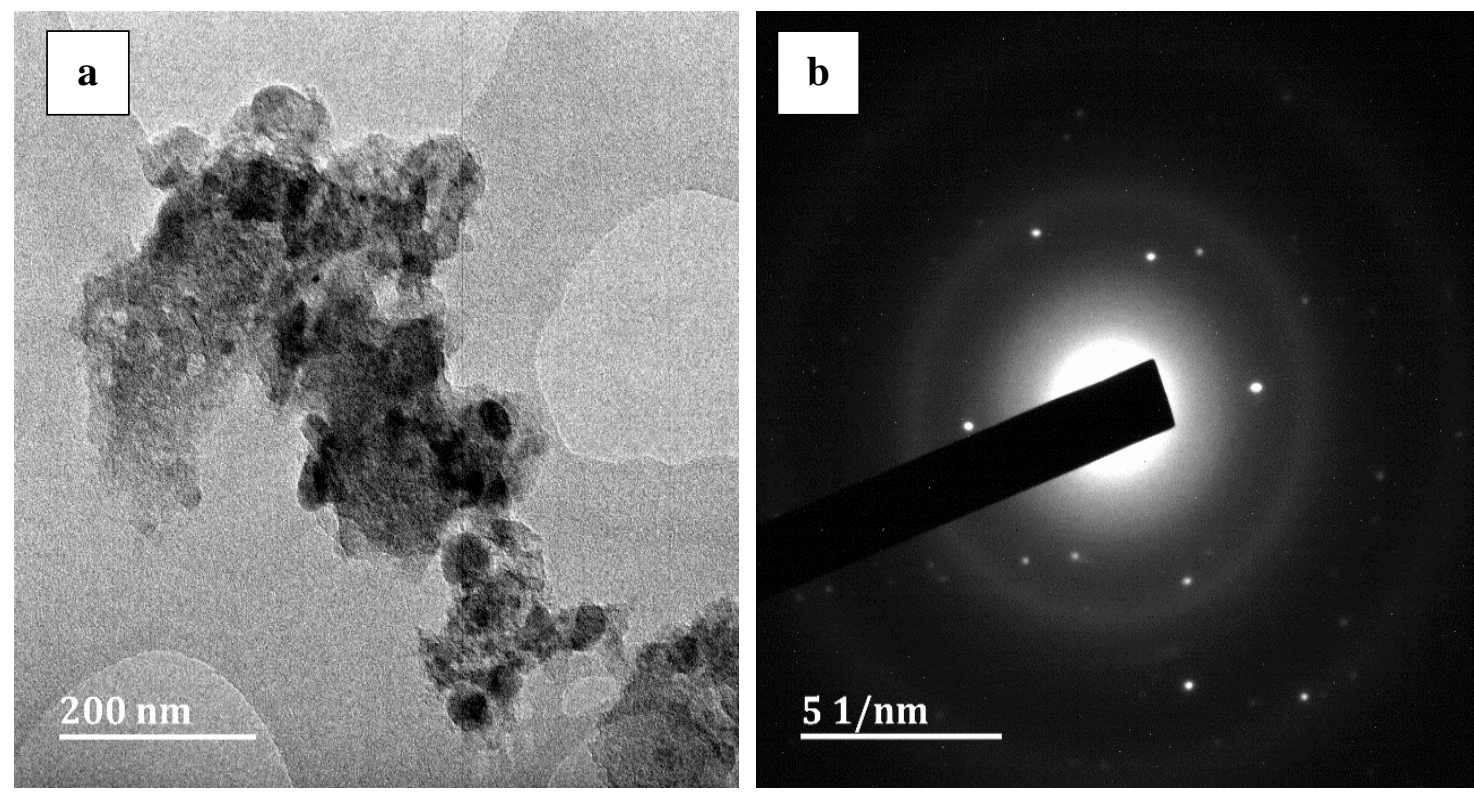

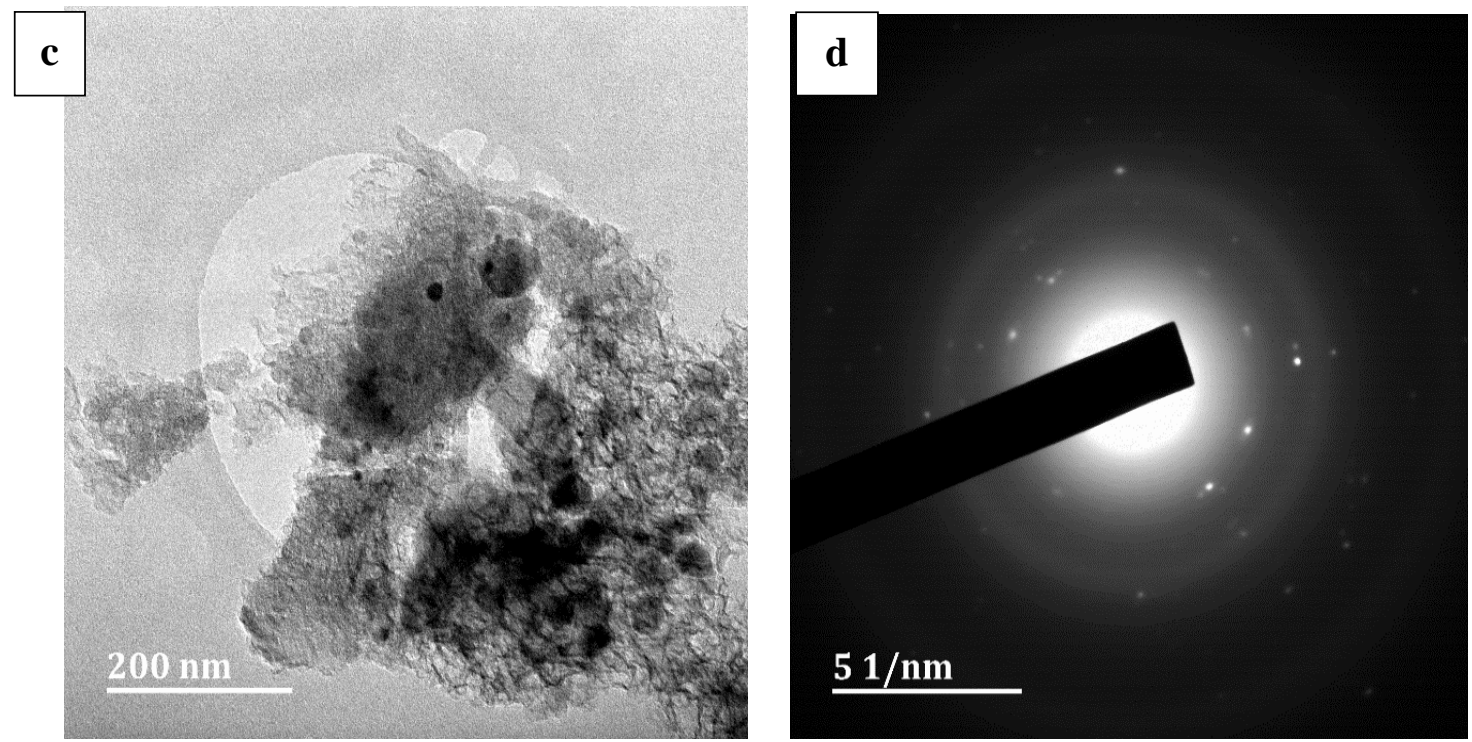

Fig. 4 (a) HRTEM of CNS synthesized at $850^{\circ} \mathrm{C}$ (b) SAED at $850^{\circ} \mathrm{C}$, (c) HRTEM of CNS synthesized at $1000{ }^{\circ} \mathrm{C}$ and (d) SAED at $1000^{\circ} \mathrm{C}$

The rings brighter areas in Fig. $4 \mathrm{~b}$ and $\mathrm{d}$ agree with the hexagonal graphite reflection 002, whereas the next constant ring observed the diffraction pattern agrees to the hexagonal graphite reflection 101. The SAED pattern from CNS samples at $850{ }^{\circ} \mathrm{C}$ as shown in Fig. $4 \mathrm{~b}$ show some sets of diffuse diffraction and unclear spots, showing that the material has a little crystalline or amorphous carbon, while the diffraction rings from Fig. $4 \mathrm{~d}$ showed that the CNS samples at $1000{ }^{\circ} \mathrm{C}$ present amorphous carbon structures and crystalline together.

F. TGA

TGA was used to examine the thermal stability of the synthesized nanomaterial at different temperatures as shown in Fig. 5. The analysis was carried out under nitrogen gas (20 $\mathrm{ml} / \mathrm{min}$ flow rate) and heating rate $\left(10{ }^{\circ} \mathrm{C} / \mathrm{min}\right)$ from $30{ }^{\circ} \mathrm{C}$ to $600{ }^{\circ} \mathrm{C}$. The synthesized nanomaterials at $700{ }^{\circ} \mathrm{C}, 850{ }^{\circ} \mathrm{C}$ and $1000{ }^{\circ} \mathrm{C}$ began to vaporize at the temperature of approximately $200{ }^{\circ} \mathrm{C}, 350{ }^{\circ} \mathrm{C}$ and $430{ }^{\circ} \mathrm{C}$ respectively. The early weight loss for all the nanomaterials happened at temperatures within 100 ${ }^{\circ} \mathrm{C}$ to $150{ }^{\circ} \mathrm{C}$ as a result of the moisture content, as well as loss of the synthesized sample functional group and other noncarbon material present in the sample. The synthesized nanospheres at $700{ }^{\circ} \mathrm{C}$ began to decay at a temperature of about $200{ }^{\circ} \mathrm{C}$ (thermal decomposition), which was caused by the presence of amorphous carbon at a lower synthesis temperature.

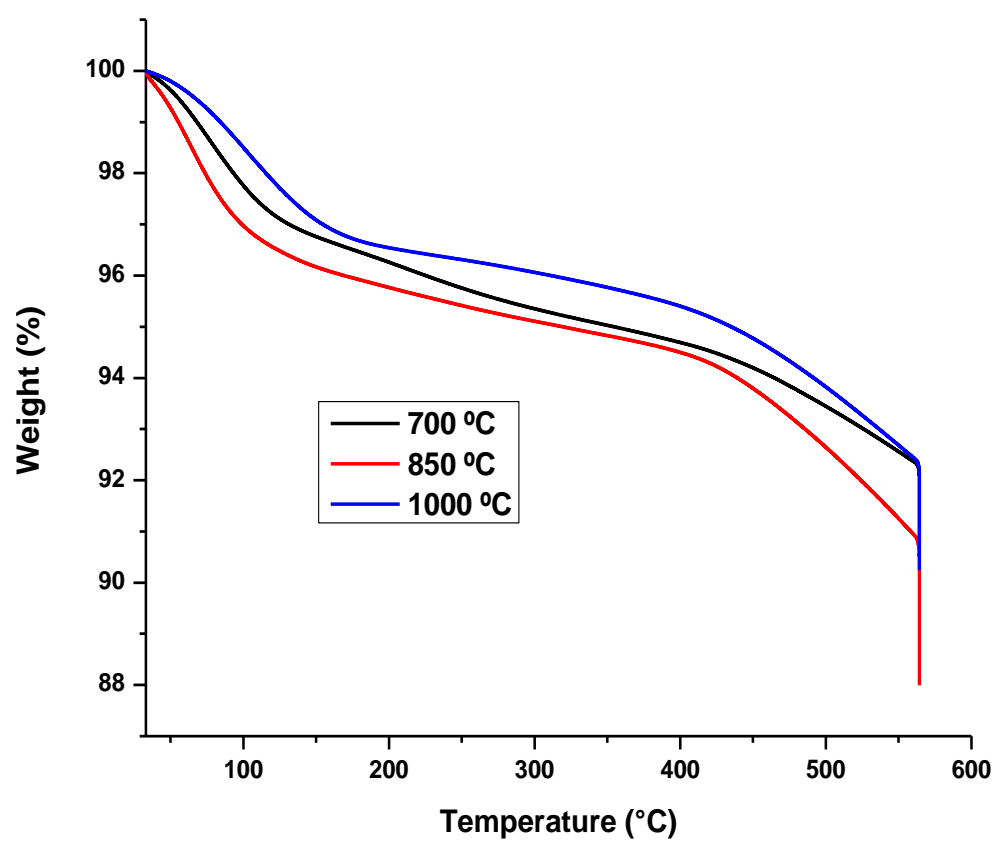

Fig. 5 TGA results for Synthesized nanomaterials at (b) $700{ }^{\circ} \mathrm{C} \mathrm{(c)850}{ }^{\circ} \mathrm{C}$ and (d) $1000{ }^{\circ} \mathrm{C}$ 
The initial degradation temperature for synthesized nanospheres prepared at $850{ }^{\circ} \mathrm{C}$ started at $350{ }^{\circ} \mathrm{C}$ due to less amorphous carbon produced by longer reaction times, which led to production of better nanospheres. At $1000{ }^{\circ} \mathrm{C}$, the synthesis temperature was high enough that almost no amorphous carbon was burned. The nanomaterial synthesized at $1000{ }^{\circ} \mathrm{C}$ started degrading at $430{ }^{\circ} \mathrm{C}$ which agrees with the decomposition of carbonaceous materials functional groups, while the whole weight loss for synthesized nanomaterials took place at $560^{\circ} \mathrm{C}$. This indicates that small diameter nanospheres were formed at low temperature and nanosphere diameter increased when the temperature of the synthesis increased.

In conclusion, the synthesized nanospheres thermal stability improved at $1000{ }^{\circ} \mathrm{C}$. The TGA results agreed with the EDX and SEM results and showed that within this temperature range, functional oxygen groups started to release, causing aromatization activation. The results also provide clear evidence that the crystalline perfection degree of CNSs increases with increasing temperature.

\section{G. FTIR}

The FTIR was measured between $400 \mathrm{~cm}^{-1}$ to $4000 \mathrm{~cm}^{-1}$ to characterize the synthesized nanomaterial functional groups using Perkin Elmer Product

Fig. 6 shows the FTIR spectrum of activated carbon PKF and synthesized nanomaterials from PKF at $700{ }^{\circ} \mathrm{C}, 850{ }^{\circ} \mathrm{C}$ and $1000{ }^{\circ} \mathrm{C}$ for $30 \mathrm{~min}$. From the FTIR result, all the PKF synthesized nanomaterials showed strong peaks at $1071 \mathrm{~cm}^{-1}$ to $1220 \mathrm{~cm}^{-1}$ which indicates different characteristics of lignin composition (O-H bending vibrations and $\mathrm{C}-\mathrm{O}$ stretching) groups, which reduced as the temperature increased.

Fig. 6 FTIR of (a) PKF carbon activated, synthesized nanomaterials at (b) $700^{\circ} \mathrm{C} \mathrm{(c)} 850^{\circ} \mathrm{C}$ and (d) $1000^{\circ} \mathrm{C}$

The FTIR spectra of all synthesized nanomaterial samples show similar vibrational modes as well as different strengths and energy changes. As shown in Fig. 6 (b) and (c), the FTIR at $700{ }^{\circ} \mathrm{C}$ and $850{ }^{\circ} \mathrm{C}$ reveals plane peaks of bending $\mathrm{C}-\mathrm{H}$ compounds between $693 \mathrm{~cm}^{-1}$ and $776 \mathrm{~cm}^{-1}$, signifying the carbon bend inside the aromatic ring. When the synthesis temperature increased $850{ }^{\circ} \mathrm{C}$ to $1000{ }^{\circ} \mathrm{C}$, the FTIR spectrum shows that there are no other peaks which indicates that the nanomaterial product has high purity.

\section{CONCLUSION}

Synthesized carbon nanospheres were successfully produced using ethanol vapor through activated carbon made from palm kernel fiber at temperatures of $700{ }^{\circ} \mathrm{C}$ to $1000{ }^{\circ} \mathrm{C}$ synthesis with $150{ }^{\circ} \mathrm{C}$ increase. The SEM analysis results showed highest purity and number of carbon-nanospheres formed at $1000{ }^{\circ} \mathrm{C}$. The results indicate that $\mathrm{CNS}$ diameter, growth rate, crystallinity and density can be affected by increase in temperature. Also, the temperature played a major role in the production of high quality and high yield CNSs. We noticed that at $1000{ }^{\circ} \mathrm{C}$, the carbon nanospheres (CNSs) were formed from synthesized nanomaterials of different sizes and shapes. The SEM images showed that the temperature growth affected the CNSs growth rate as well as their diameter and density. As the temperature increased, the increase in growth rate of synthesized CNSs was most likely due to the increased carbon diffusion and reaction rate. It was also discovered that the temperature was an influential factor in regulating the structure of the CNSs. 
In conclusion, synthesis temperature greatly affects the diameter, density and crystallinity of carbon nanomaterials synthesized from PKF. The synthesis temperature of $1000{ }^{\circ} \mathrm{C}$ can be considered as the ideal temperature for production of high quality and high yield CNSs. The EDX result showed the presence of iron (Fe) in the sample which makes PKF nanomaterials good candidates as additive material in the production of brake pads.

\section{NOMENCLATURE}

$\begin{array}{ll}\text { CNS } & \text { Carbon Nanospheres } \\ \text { PKF } & \text { Palm Kernel Fiber } \\ \text { CF } & \text { Carbon Fiber } \\ \text { O } & \text { Oxygen } \\ \text { C } & \text { Carbon } \\ \text { K } & \text { Potassium } \\ \text { CO }_{2} & \text { Carbon dioxide } \\ \text { SI } & \text { Silicon } \\ \text { Fe } & \text { Iron } \\ \text { SEM } & \text { Scanning Electron Microscope } \\ \text { XRD } & \text { X-Ray Diffraction } \\ \text { EDX } & \text { Energy Dispersive X-Ray } \\ \text { CVD } & \text { Chemical vapor deposition } \\ \text { TGA } & \text { Thermo-gravimetric analysis } \\ \text { SAED } & \text { Selected Area Electron Diffraction } \\ \text { CNTs } & \text { Carbon nanotubes } \\ \text { CNPs } & \text { Carbon-Nanoparticles } \\ \text { FEGSEM } & \text { Field Emission Gun Scanning } \\ & \text { Microscope } \\ & \text { Spectron } \\ & \end{array}$

FTIR Spectroscopy Fourier Transform Infrared Microscopy

TEM Transmission Electron Microscopy

HRTEM High-Resolution Transmission Electron Microscopy

\section{REFERENCES}

[1] S. Iijima, "Helical microtubules of graphitic carbon," Nature, vol. 354, p. 56, 1991.

[2] S. Awasthi, K. Awasthi, R. Kumar, and O. Srivastava, "Functionalization effects on the electrical properties of multi-walled carbon nanotubepolyacrylamide composites," J. Nanosci. Nanotechnol., vol. 9, pp. 5455-5460, 2009.

[3] X.-W. Chen, O. Timpe, S. B. Hamid, R. Schlögl, and D. S. Su, "Direct synthesis of carbon nanofibers on modified biomass-derived activated carbon," Carbon, vol. 47, pp. 340-343, 2009.

[4] A. Thess, R. Lee, P. Nikolaev, H. Dai, P. Petit, J. Robert, et al., "Crystalline ropes of metallic carbon nanotubes," Science, vol. 273, pp. 483-487, 1996.

[5] T. Ebbesen and P. Ajayan, "Large-scale synthesis of carbon nanotubes," Nature, vol. 358, p. 220, 1992.

[6] K. Awasthi, R. Kumar, H. Raghubanshi, S. Awasthi, R. Pandey, D. Singh, et al., "Synthesis of nanocarbon (nanotubes, nanofibres, graphene) materials," Bull. Mater. Sci., vol. 34, p. 607, 2011.

[7] C. He, N. Zhao, C. Shi, and S. Song, "Fabrication of carbon nanomaterials by chemical vapor deposition," J. Alloys Compd., vol. 484, pp. 6-11, 2009.

[8] C. L. Cheung, A. Kurtz, H. Park, and C. M. Lieber, "Diameter-controlled synthesis of carbon nanotubes," J. Phys. Chem. B, vol. 106, pp. 2429-2433, 2002.

[9] D. Kondo, S. Sato, and Y. Awano, "Low-temperature synthesis of single-walled carbon nanotubes with a narrow diameter distribution using size-classified catalyst nanoparticles," Chem. Phys. Lett., vol. 422, pp. 481-487, 2006.

[10] W.-H. Chiang and R. M. Sankaran, "In-flight dimensional tuning of metal nanoparticles by microplasma synthesis for selective production of diameter-controlled carbon nanotubes," J. Phys. Chem. C, vol. 112, pp. 17920-17925, 2008.

[11] E. W. Wong, P. E. Sheehan, and C. M. Lieber, "Nanobeam mechanics: elasticity, strength, and toughness of nanorods and nanotubes," Science, vol. 277, pp. 1971-1975, 1997.

[12] M. S. Dresselhaus, G. Dresselhaus, and P. C. Eklund, Science of Fullerenes and Carbon Nanotubes: Their Properties and Applications. Amsterdam: Elsevier, 1996.

[13] M. J. Treacy, T. Ebbesen, and J. Gibson, "Exceptionally high Young's modulus observed for individual carbon nanotubes," Nature, vol. 381, p. 678, 1996.

[14] J. Njuguna, K. Pielichowski, and S. Desai, "Nanofiller- reinforced polymer nanocomposites," Polym. Adv. Technol., vol. 19, pp. 947-959, 2008.

[15] Q. Liu and Y. Fang, "New technique of synthesizing single-walled carbon nanotubes from ethanol using fluidized-bed over $\mathrm{Fe}-\mathrm{Mo} / \mathrm{MgO}$ catalyst," Spectrochimica Acta A, vol. 64, pp. 296-300, 2006.

[16] S. Maruyama, R. Kojima, Y. Miyauchi, S. Chiashi, and M. Kohno, "Low-temperature synthesis of highpurity single-walled carbon nanotubes from alcohol," Chem. Phys. Lett, vol. 360, pp. 229-234, 2002.

[17] S. S. Madani, K. Zare, and M. Ghoranneviss, "Role of growth temperature in CVD synthesis of Carbon 
nanotubes from Ni-Co bimetallic catalysts," Int. J. Nano Dimension, vol. 7, pp. 240-246, 2016.

[18] C. J. Lee, J. Park, Y. Huh, and J. Y. Lee, "Temperature effect on the growth of carbon nanotubes using thermal chemical vapor deposition," Chem. Phys. Lett, vol. 343, pp. 33-38, 2001.

[19] Y. T. Lee, J. Park, Y. S. Choi, H. Ryu, and H. J. Lee, "Temperature-dependent growth of vertically aligned carbon nanotubes in the range $800-1100^{\circ} \mathrm{C}, " \mathrm{~J}$. Phys. Chem. B, vol. 106, pp. 7614-7618, 2002.

[20] A. Muataz, F. Ahmadun, C. Guan, E. Mahdi, and A. Rinaldi, "Effect of reaction temperature on the production of carbon nanotubes," Nano, vol. 1, pp. 251-257, 2006.

[21] J. O. Alves, J. A. S. Tenório, C. Zhuo, and Y. A. Levendis, "Characterization of nanomaterials produced from sugarcane bagasse," J. Mater. Res. Technol., vol. 1, pp. 31-34, 2012.

[22] I. Abdullahi, N. Sakulchaicharoen, and J. E. Herrera, "Selective synthesis of single-walled carbon nanotubes on $\mathrm{Fe}-\mathrm{MgO}$ catalyst by chemical vapor deposition of methane," Diamond Relat. Mater., vol. 41, pp. 84-93, 2014.

[23] N. Jeong, Y. Seo, and J. Lee, "Vertically aligned carbon nanotubes synthesized by the thermal pyrolysis with an ultrasonic evaporator," Diamond Relat. Mater., vol. 16, pp. 600-608, 2007.

[24] M. Shamsudin, N. Asli, S. Abdullah, S. Yahya, and M. Rusop, "Effect of synthesis temperature on the growth iron-filled carbon nanotubes as evidenced by structural, micro-raman, and thermogravimetric analyses," Adv. Condens. Matter Phys., vol. 2012, 2012.

[25] L. Sun, S. Xie, J. Mao, Z. Pan, B. Chang, W. Zhou, et al., "Effects of temperature oscillations on the growth of carbon nanotubes by chemical vapor deposition," Appl. Phys. Lett., vol. 76, pp. 828-830, 2000.

[26] M. Sani, M. Rahman, M. Noor, K. Kadirgama, and M. Izham, "IOP Conference Series: Materials Science and Engineering," ed: IOP Publishing, 2011.

[27] Q. N. Pham, L. S. Larkin, C. C. Lisboa, C. B. Saltonstall, L. Qiu, J. D. Schuler, et al., "Effect of growth temperature on the synthesis of carbon nanotube arrays and amorphous carbon for thermal applications," Physica Status Solidi (a), vol. 214, p. 1600852, 2017.

[28] B. Zhao, Y. Liang, C. Jiang, J. Li, and J. Yang, "Effects of growth temperature on carbon nanotube forests synthesized by water-assisted chemical vapor deposition," Nanosci. Nanotechnol. Lett., vol. 6, pp. 488-492, 2014.

[29] Y. Jiang and C. Lan, "Low temperature synthesis of multiwall carbon nanotubes from carbonaceous solid prepared by sol-gel autocombustion," Mater. Lett., vol. 157 , pp. 269-272, 2015.

[30] S. Alam, S. Bangash, and F. Bangash, "Elemental analysis of activated carbon by EDS spectrophotometry and X-rays diffraction," J. Chem. Soc. Pak, vol. 31, pp. 46-58, 2009G. 